(1)

George Fox

UNIVERSITY
Digital Commons @ George Fox University

Examining Relationships Between Resilience Protective Factors and Moral Distress Among Nursing Students

Lorretta Krautscheid,

Laura Mood

Susan M. McLennon

Taylor C. Mossman

Marie Wagner

See next page for additional authors

Follow this and additional works at: https://digitalcommons.georgefox.edu/sn_fac

Part of the Education Commons, and the Nursing Commons 
Authors

Lorretta Krautscheid;; Laura Mood; Susan M. McLennon; Taylor C. Mossman; Marie Wagner; and Jessica Wode 


\title{
Examining Relationships Between Resilience Protective Factors and Moral Distress Among Nursing Students
}

\author{
Lorretta Krautscheid, Laura Mood, Susan M. McLennon, Taylor C. Mossman, Marie Wagner, and Jessica Wode
}

\begin{abstract}
A correlation pilot study was conducted to examine relationships between resilience protective factors and moral distress associated with clinical practica in nursing students. Aggregate moral distress rating was $x=3.67$. Two of four resilience protective factor subcategories demonstrated significant inverse correlations with moral distress rating. Inverse correlations were found between social support and moral distress $(r=-.27, p<.05)$ and between goal efficacy and moral distress $(r=-.37, p<.01)$. The findings should help educators prioritize resilience-enhancing educational strategies.
\end{abstract}

KEY WORDS Moral Distress - Nursing Education - Nursing Students - Resilience

A pproximately 17.5 percent of newly registered nurses leave their initial job within the first year of practice (Kovner, Brewer, Fatehi, \& Jun, 2014). Moral distress, or feeling constrained from acting upon one's ethical knowing (Jameton, 1984), is associated with powerlessness and burnout and may contribute to workforce attrition (Rushton \& Kurtz, 2015). Enhancing resilience protective factors (RPFs), defined as social and personal capacities to recover, adapt, and persist amidst adversity (Madewell \& PonceGarcia, 2016), may help nurses mitigate moral distress. According to Lachman (2016), resilience assists persons identify ethical dilemmas, speak up effectively, and take action.

A variety of resilience education interventions have been recommended, but scholars have yet to specify which resilience educational strategies most effectively attenuate moral distress. In this pilot study, we sought to examine relationships between RPF scores and moral distress ratings among baccalaureate nursing students. Such evidence is needed to guide curricular revisions and prioritize allocation of educational resources.

\footnotetext{
About the Authors Lorretta Krautscheid, PhD, RN, CNE, is an associate professor, University of Portland School of Nursing, Portland, Oregon. Laura Mood, $P h D, R N$, is an assistant professor, University of Portland School of Nursing. Susan M. McLennon, PhD, ANP-BC, is an associate professor, University of Tennessee, Knoxville, Tennessee. Taylor $C$. Mossman, BSN, RN, is a registered nurse, Providence St. Vincent Medical Center, Portland, Oregon. Marie Wagner, BSN, RN, is a registered nurse, Providence Portland Medical Center, Portland, Oregon. Jessica Wode, MA, is housing coordinator, University of Portland, Portland, Oregon. For more information, contact Dr. Krautscheid at krautsch@up.edu. The authors have declared no conflict of interest.

Copyright (C) 2019 National League for Nursing doi: 10.1097/01.NEP.0000000000000471
}

\section{LITERATURE REVIEW}

A literature search of allied health databases was conducted using the following key words: moral distress, nurse, student, retention, attrition, resilience, moral resilience, and resilience education. The search returned evidence about moral distress among nursing students and resilience education suggestions. No published studies assessed relationships between RPFs and moral distress among nursing students.

Student nurse moral distress and clinical situations contributing to such distress have been reported (Grady, 2014; Krautscheid et al., 2017; Sasso, Bagnasco, Bianchi, Bressan, \& Carnevale, 2016). Research recommendations call for nurse educators to incorporate resilience education within curricula, assisting students to cope proactively with adversities inherently associated with ethical issues. The literature suggests educators may support RPFs through a number of educational interventions (Stephens, 2013; Thomas \& Revell, 2016). These include enhancing social support, mindfulness, spiritual well-being, self-efficacy, conflict management strategies, and ethical decision-making capacities through the use of such strategies as narrative story-telling with reflection on action and creating opportunities for cumulative successes (Lachman, 2016; Stephens, 2012, 2013; Thomas \& Revell, 2016). Although scholars have recommended a variety of resilience educational strategies to attenuate moral distress, research guiding educational priorities is limited.

\section{METHOD}

This correlational study sought to identify if significant associations exist between RPF scores and moral distress ratings among BSN students. Two instruments were used in this study. The Scale of Protective Factors (SPF) was used to measure RPFs; this previously tested tool (Cronbach's $\alpha=.94)$ effectively measures resilience attributes among college-age students (Madewell \& Ponce-Garcia, 2016). The SPF uses a 7-point Likert scale (1 = disagree completely, $7=$ completely agree) to measure items in four subscales (Social 
Skills, Social Support, Goal Efficacy, Planning/Prioritizing Behaviors). Subscale scores less than 5 or total SPF scores less than 20 indicate low resilience.

The moral distress thermometer (MDT), which has "demonstrated acceptable reliability and support for concurrent validity" (Wocial \& Weaver, 2012, p. 171), was used to measure moral distress ratings. The MDT measures moral distress on a scale of 0 to 10 , with associated verbal anchors $(0=$ no moral distress and $10=$ worst possible distress experienced). Appropriate permissions were obtained to use the SPF and MDT instruments for this study.

\section{Sampling, Data Collection, and Data Analysis}

Participants were senior-level BSN students enrolled at a private uni-versity (University A) and at a public university (University B). Students in both programs were progressing through a similar curriculum and the same grade level within their respective programs. Each site's institutional review board issued approval for this pilot study prior to recruitment. Investigators adhered to all ethical guidelines for the con-duct of human subject research.

Convenience and homogenous purposive sampling strategies were used. Senior-level students who met inclusion criteria (i.e., 18 years of age or older, completed at least 250 clinical practice hours, and enrolled in BSN program) received an institutional review board-approved recruitment script via email. Participation was voluntary and occurred outside class time; consent was implied when participants completed and submitted both instruments. To ensure anonymity, participants were assigned a unique identification number that was stored in an electronic codebook on a password-protected computer.

Numerical SPF and MDT data were analyzed using SPSS 20. Relationships between SPF scores and MDT ratings were measured via two-tailed Pearson correlations. Paired $t$-tests were used to compare the difference in means for both the SPF scores and the MDT ratings.

\section{FINDINGS}

Of the 60 participants, 24 were from University A and 36 were from University B. University A participants included 20 women (83 percent) and 4 men (16 percent), with a mean age of 24.9 years. University $B$ participants consisted of 31 women (86 percent) and 5 men (13 percent), with a mean age of 26.1 years.

\section{SPF and MDT Data}

RPFs subscores and total scores as measured by the SPF were not significantly different between the two sites. Total SPF mean scores were 21.79 at University A and 22.12 at University B $(p=.45)$. The mean moral distress rating between both sites was significantly different $(x=3.67, p<.001)$ : 4.59 for University A and 3.03 for University B.

\section{Relationship Between RPFs and Moral Distress}

When combining data from both sites, significant inverse correlations were noted between two of the four SPF subscale scores and moral distress ratings. Table 1 provides correlation statistics demonstrating weak inverse correlations between social support and moral distress $(r=-.27, p<.05)$ and between goal efficacy and moral distress $(r=-.37, p<.01)$. The total SPF score also demonstrated a weak inverse correlation with moral distress $(r=-.24, p<.05)$. No significant relationships were identified between social skills and moral distress or between planning/prioritizing behavior and moral distress (Table 1).

\section{DISCUSSION, LIMITATIONS, AND RECOMMENDATIONS}

Study findings resulted in new evidence about relationships between RPFs and moral distress. The nursing student resilience model (Stephens, 2013) aligns with study findings, emphasizing the iterative relationships between enhanced protective factors and enhanced coping abilities amidst adversity. Stephens' (2013) model and study findings guide educators to prioritize educational interventions, allocating resources toward strategies that emphasize social support and goal efficacy RPFs. Social support resilience strategies should emphasize developing supportive and encouraging relationships among all parties in the learning environment (e.g., students, learning peers, didactic and clinical faculty). Learning activities would emphasize developing social cohesion and teamwork capacities, initiating and successfully navigating collegial conversations, and managing interdisciplinary conflict (Madewell \& Ponce-Garcia, 2016; Stephens, 2013; Thomas \& Revell, 2016). Goal efficacy resilience education strategies should promote students' confidence in their ability to accomplish goals and succeed (Madewell \& PonceGarcia, 2016). With specific attention to RPFs and moral distress, educational recommendations include rehearsing ethical dilemmas via role-play activities in didactic settings and subsequent rehearsal

Table 1: Correlations Between the Scale of Protective Factors and Moral Distress Thermometer Scores, Site A and Site B Data Combined

\begin{tabular}{|c|c|c|c|c|c|}
\hline Measure & 1 & 2 & 3 & 4 & 5 \\
\hline 1. Social skills subscore & - & & & & \\
\hline 2. Social support subscore & $.47^{\star \star}$ & - & & & \\
\hline 3. Goal efficacy subscore & $.64^{\star \star}$ & $.59^{\star \star}$ & - & & \\
\hline 4. Planning/prioritizing behavior subscore & $.29^{*}$ & $.33^{\star \star}$ & $.54^{\star \star}$ & - & \\
\hline 5. Total score & $.77^{\star \star}$ & $.75^{\star \star}$ & $.88^{\star \star}$ & $.71^{\star \star}$ & - \\
\hline 6. Moral distress rating & -.13 & $-.27^{\star}$ & $-.37^{\star \star}$ & .01 & $-.24^{*}$ \\
\hline
\end{tabular}


of ethical situations via high-fidelity simulation. Such intentional strategies create opportunities for students to rehearse, receive formative feedback, develop confidence, nuture moral sensitivity, and enhance resilience through cumulative successes (Stephens, 2013).

Mean moral distress ratings were significantly higher at University A. A small sample size and nonprobability sampling provide conceivable explanations for the noted difference, raising concerns about selection bias and presenting a limitation to study findings. A recommendation for future research is to repeat the study at multiple sites with a larger sample, using random sampling strategies.

Prioritizing specific resilience education strategies has the potential to maximize available educational resources while also enhancing RPFs among student nurses. Targeted educational activities have the potential to minimize the effects of moral distress, promote workforce retention, and ultimately strengthen patient care outcomes. Importantly, nurse educators are key to achieving these outcomes via the development and integration of resilience education strategies, which, in turn, inspire moral agency and everyday ethical practice of future nurses.

\section{REFERENCES}

Grady, A. (2014). Experiencing moral distress as a student nurse. Imprint, 61(2), 40-42. Jameton, A. (1984). Nursing practice: The ethical issues. Englewood Cliff, NJ:

Prentice Hall.
Kovner, C. T., Brewer, C. S., Fatehi, F., \& Jun, J. (2014). What does nurse turnover mean and what is the rate. Policy, Politics, \& Nursing Practice, 15(3-4), 64-71. doi.org/10.1177/1527154414547953

Krautscheid, L., DeMeester, D., Orton, V., Smith, A., Livingston, C., \& McLennon, S. M. (2017). Moral distress among baccalaureate nursing students and associated factors: A descriptive multi-site study. Nursing Education Perspectives, 38(6), 313-319. doi:10.1097/01.NEP.0000000000000214

Lachman, V. D. (2016). Moral resilience: Managing and preventing moral distress and moral residue. Medsurg Nursing, 25(2), 121-124.

Madewell, A. N., \& Ponce-Garcia, E. (2016). Assessing resilience in emerging adulthood: The Resilience Scale (RS), Connor-Davidson Resilience Scale (CD-RISC), and Scale of Protective Factors (SPF). Personality and Individual Differences, 97, 249-255. doi.org/10.1016/j.paid.2016.03.036

Rushton, C., \& Kurtz, M. (2015). Moral distress and you: Supporting ethical practice and moral resilience in nursing. Silver Spring, MD: Nursebooks.

Sasso, L., Bagnasco, A., Bianchi, M., Bressan, V., \& Carnevale, F. (2016). Moral distress in undergraduate nursing students: A systematic review. Nursing Ethics, 23(5), 523-534.

Stephens, T. (2012). Increasing resilience in adolescent nursing students (Unpublished doctoral dissertation). The University of Tennessee, Knoxville.

Stephens, T. M. (2013). Nursing student resilience: A concept clarification. Nursing Forum, 48(2), 125-133.

Thomas, L. J., \& Revell, S. H. (2016). Resilience in nursing students: An integrative review. Nurse Education Today, 36, 457-462.

Wocial, L. D., \& Weaver, M. T. (2012). Development and psychometric testing of a new tool for detecting moral distress: The moral distress thermometer. Journal of Advanced Nursing, 69(1), 167-174. doi:10.111/j.136502648.2012.06036.x 